\title{
Situs inversus: When an incidental finding is not so incidental
}

\author{
Phil Robinson
}

Victorian PCD diagnostic service, Department of Respiratory and Sleep Medicine, Royal Children's Hospital, Murdoch Children's Research Institute, and Department of Paediatrics, University of Melbourne, Melbourne, Australia.

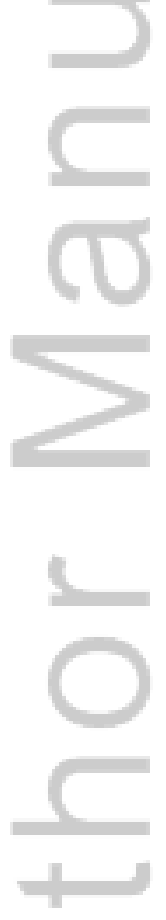

Address for correspondence:

A/Professor Phil Robinson

Department of Respiratory and Sleep Medicine,

Royal Children's Hospital,

Parkville 3025

This is the author manuscript accepted for publication and has undergone full peer review but has not been through the copyediting, typesetting, pagination and proofreading process, which may lead to differences between this version and the Version of Record. Please cite this article as doi: $10.1111 /$ jpc.13591

This article is protected by copyright. All rights reserved. 
Fax: 61393459154

Email: phil.robinson@rch.org.au

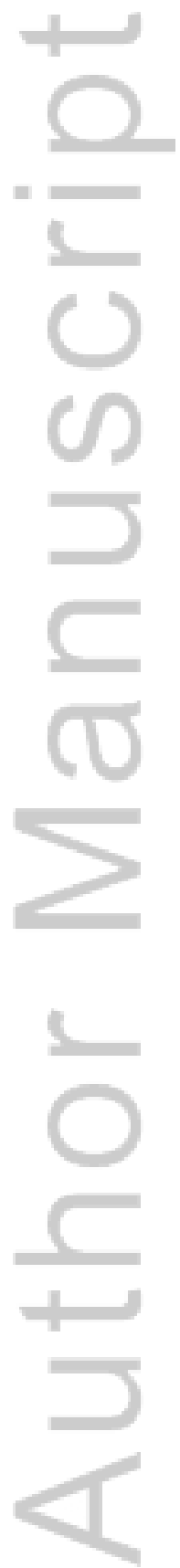

This article is protected by copyright. All rights reserved. 


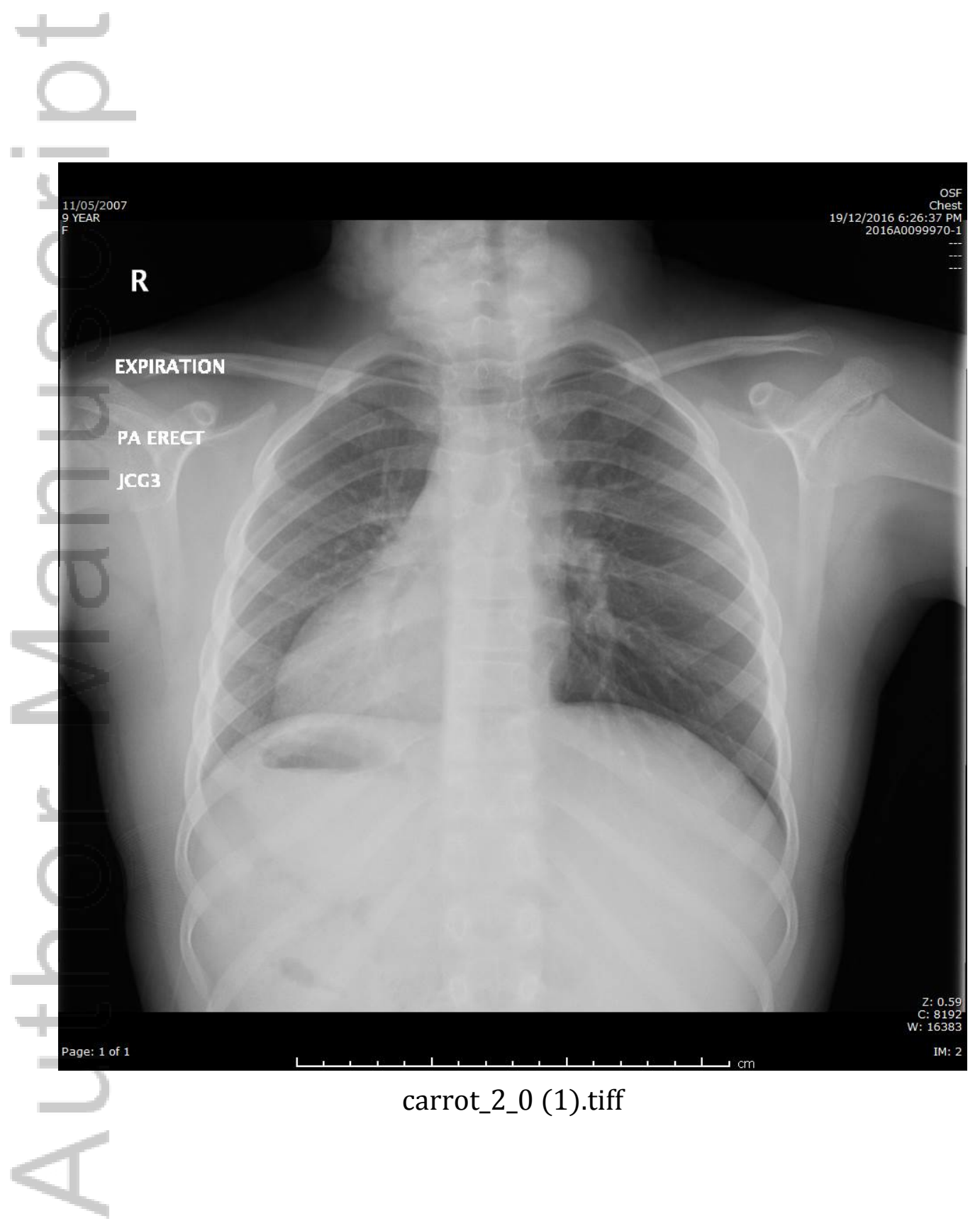

This article is protected by copyright. All rights reserved. 


\section{Situs inversus: When an incidental finding is not so incidental}

\section{Introduction}

A 9-year-old girl presented to the emergency department of a local general hospital with a history of choking on a piece of uncooked carrot. She had been eating a small carrot stick when a friend had caused her to laugh. She immediately choked on the carrot and coughed forcefully for several minutes. She then experienced regular bouts of dry irritant coughing over the next hour and attended the emergency department for assessment. According to the notes taken by the attending medical staff she had been previously well and had no significant past medical history. She was described as having a mild increased work of breathing with no audible wheezing or stridor and examination of her chest was described as normal with no differential air entry noted. Given the high suspicion of inhalation of a fragment of the carrot a chest X-ray was obtained - see Fig 1.

The CXR showed hyperinflation of the left lung with loss of clarity of the left main stem bronchus. Situs inversus totalis was also noted. The child was transferred to a tertiary pediatric hospital where a respiratory opinion was obtained. As it was felt the likelihood of an inhaled foreign body was high the child was taken to theatre where a large carrot fragment obstructing a major division of the left main stem bronchus was removed without difficulty. On examination it was noted that the bronchial anatomy on the left side of the chest was identical to right bronchial anatomy in situs solitus. The carrot fragment thus was obstructing the left side equivalent of the right middle lobe bronchus.

The patient made an uneventful recovery and was discharged the following day. A follow up appointment was made to the hospitals PCD diagnostic clinic. At the clinic a detailed history was obtained. The child was described as having lifelong upper and lower respiratory symptoms for which the mother had consulted medical services on multiple occasions. A CXR had never been performed. The child had been born at term by normal vaginal delivery but had developed nasal discharge from day 2 of life which required regular nasal toilet for feeding and sleeping. The child had experienced recurrent episodes of otitis media commencing at around 6 months of age and a moderate hearing loss had been detected at the age of 5 years. A daily productive cough had been present from infancy and had been labeled and treated as asthma by several local doctors with no apparent benefit. There was no family history of underlying lung disease, situs inversus or PCD.

On examination a right-sided apex beat and heart sounds were noted. Lung fields were clear on auscultation. Exhaled nasal nitric oxide was measured and a value of $26 \mathrm{ppb}$ obtained. A level less than $150 \mathrm{ppb}$ is considered highly suspicious of PCD. Nasal brushing was then performed and the obtained epithelia cell sample examined under light microscopy for ciliary beat frequency and beat synchronicity. Samples were then processed for electron microscopic 
assessment of cilial ultra-structure. Based on these results and the compatible clinical picture a diagnosis of PCD was made.

\section{Discussion}

Situs inversus is estimated to occur at 1 in 10,000 live births however many cases may remain undiagnosed until radiology or detailed clinical assessment of the chest reveals the organ displacement. In this child's case it would appear however that despite regular and chronic symptoms of upper and lower airway suppuration the possibility of an underlying condition such as PCD was not considered. Between $20-25 \%$ of patients with situs inversus totalis will have evidence of PCD on detailed testing. Intentional guidelines suggest that any patient found to have situs inversus, even on incidental testing, such as CXR for other clinical indications, be referred for testing to a PCD diagnostic clinic employing high speed videographic assessment of beat frequency and synchronicity as well as electron microscopic assessment of cilial ultrastructure. (1) Airway cilia beat at between 8 and $15 \mathrm{HZ}$ and assessment of beat frequency and synchronicity requires high speed recording usually at around 500 frames per second with slow detailed play back to make full assessment of beat frequency and synchronicity.

For the clinician the recommendation that all patients found to have situs inversus totalis should be referred to diagnostic centers for assessment ensures that early diagnosis and appropriate treatment and follow up is instituted. However when faced with the child presenting with symptoms of regular cough and or nasal symptoms, such as this child did on several previous occasions, when should PCD, an uncommon condition, be considered? While chronic cough in young children is a frequent presenting symptom to medical services and often related to commoner conditions such as recurrent viral respiratory tract infections, and even conditions such as cystic fibrosis and immune defects, several diagnostic algorithms have been proposed to help identify patients who are at increased risk of having PCD. In one protocol it is suggested that patients with two or more of the following be referred for diagnostic studies 1) unexplained neonatal respiratory distress in a term infant, 2) chronic nasal congestion problems and otitis media from an early age (generally first year of life), 3) chronic daily cough that does not vary seasonally or respond to short course of antibiotics and 4) presence of heterotaxy. The patient described in this report has 3 positive factors and would appropriately be referred for testing. A similar diagnostic algorithm suggested by Behan for children with a chronic wet cough is PICADAR (PrImary CiliARy DyskinesiA Rule) which allocates scores for 7 suggestive clinical parameters including symptoms of upper and lower airway suppurative disease, laterality defects and neonatal respiratory distress in term births. A higher score increases the likelihood of PCD. The patient in this current report would score a PICADAR of 8 which gives a positive predictive value of 0.85 and a negative predictive value of 0.65 . Clearly the importance of a detailed physical examination cannot be understated. This child had on numerous occasions had ascultatory assessment of chest sounds without once the displaced apex beat being noted. Examining a child with such a common 
symptom as a chronic cough still requires accurate attention to both heart and breath sounds as many important indicators of specific underlying conditions can be present.

This illustrative case highlights the importance of taking a detailed medical history and an accurate medical examination even when the presenting feature may not suggest chronic or underlying medical issues. The case further highlights the importance of awareness of the association of significant conditions, including PCD, in patients who are found to have situs inversus. PCD is an uncommon condition which presents with symptoms commonly expressed in young children- chronic cough and otitis media. Awareness of important predictive features on history and or clinical examination will allow appropriate referral of patients to diagnostic services.

\section{Summary learning points}

1) Up to a quarter of patients with situs inversus will be found to also have PCD on testing. Patients found to have situs inversus should be referred for PCD testing.

2) Specific questioning concerning the nature of cough and associated upper airway symptoms are important in identifying patients who may be at increased risk of PCD.

3) PCD diagnosis requires detailed laboratory testing for diagnosis.

4) Chronic nasal congestion and chronic wet cough from early on in life are strong suggestive symptoms of PCD.

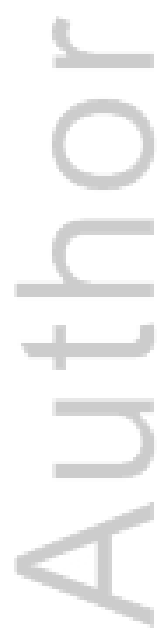

This article is protected by copyright. All rights reserved. 


\section{References}

1: Shapiro AJ, Zariwala MA, Ferkol T, Davis SD, Sagel SD, Dell SD, Rosenfeld M, Olivier KN, Milla C, Daniel SJ, Kimple AJ, Manion M, Knowles MR, Leigh MW. Genetic Disorders of Mucociliary Clearance Consortium. Diagnosis, monitoring, and treatment of primary ciliary dyskinesia: PCD foundation consensus recommendations based on state of the art review. Pediatric Pulmonology. 51(2):115-32, 2016 Feb.

2: Behan L, Dimitrov BD, Kuehni CE, Hogg C, Carroll M, Evans HJ, Goutaki M, Harris A, Packham S, Walker WT, Lucas JS. PICADAR: a diagnostic predictive tool for primary ciliary dyskinesia. European Respiratory Journal. 47(4):1103-12, 2016 Apr.
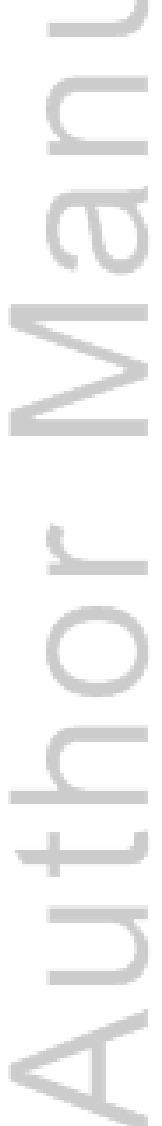

This article is protected by copyright. All rights reserved. 


\section{University Library}

\section{- M M I E E R VA A gateway to Melbourne's research publications}

Minerva Access is the Institutional Repository of The University of Melbourne

\section{Author/s:}

Robinson, $\mathrm{P}$

Title:

Situs inversus: When an incidental finding is not so incidental

Date:

2017-07-01

Citation:

Robinson, P. (2017). Situs inversus: When an incidental finding is not so incidental. JOURNAL OF PAEDIATRICS AND CHILD HEALTH, 53 (7), pp.715-716. https:// doi.org/10.1111/jpc.13591.

Persistent Link:

http://hdl.handle.net/11343/293130 